\title{
Optimal International Normalized Ratio for Warfarin Therapy in Elderly Korean Patients with Non-Valvular Atrial Fibrillation
}

Won Suk Choi, MD; Jae Hee Kim, MD; Se Yong Jang, MD; Sun Hee Park, MD; Myung Hwan Bae, MD; Jang Hoon Lee, MD; Dong Heon Yang, MD; Hun Sik Park, MD; Yongkeun Cho, MD; Shung Chull Chae, MD

Department of Internal Medicine, Kyungpook National University Hospital, Republic of Korea
Received: October 7, 2016

Revision Received: October 28, 2016

Accepted: November 8, 2016

Correspondence: Myung Hwan Bae, MD

Department of Internal Medicine, Kyungpook

National University Hospital, 130 Dongduk-ro, Jung-Ku, Daegu, 41944, Republic of Korea.

Tel: +82-53-200-5525 Fax: +82-53-426-2046

E-mail: bmh0325@dreamwiz.com

\section{ABSTRACT}

Background and Objectives: Optimal international normalized ratio (INR) in elderly atrial fibrillation (AF) patients at higher risk of hemorrhagic events remains unclear. We investigated the efficacy and safety of low-intensity warfarin therapy (target international normalized ratio [INR], 1.6-2.6) in elderly Korean patients with nonvalvular AF (NVAF).

Subjects and Methods: We enrolled 528 NVAF patients (mean age, $67 \pm 9$ years; 361 men) who were actively taking warfarin. Major events were defined based on the annual rates of ischemic stroke, systemic embolism, and major bleeding events requiring blood transfusion or hospitalization. Time in therapeutic range (TTR) was $45 \pm 19 \%$ for all patients.

Results: Ischemic stroke and systemic embolism occurred in 20 patients with INR between 1.00 and 2.44 (16 ischemic strokes and 4 systemic embolisms) and major bleeding in 37 patients with INR between 1.74 and no coagulation (exceed laboratory detection capability, more than 10 [7 intracranial hemorrhages, 21 gastrointestinal bleedings, and 9 others]). Incidence rates of ischemic or hemorrhagic events at INR $<2.00,2-3$, and $>3$ were $3.0 \%, 1.4 \%$, and $20.1 \%$ per year, respectively. In patients who were $\geq 70$ years old, $\mathrm{CHADS}_{2}, \mathrm{CHA}_{2} \mathrm{DS}_{2} \mathrm{VASc}$, and HAS-BLED scores were significantly higher compared with those in patients who were $<70$ years old. When we applied the INR between 1.6 and 2.6, as recommended by the Japanese AF Guideline for patients $\geq 70$ years old, the TTR increased from $43.8 \%$ to $58.6 \%$. In addition, ischemic or hemorrhagic event rates decreased from $1.9 \%$ to $1.2 \%$ within the optimal INR range.

Conclusion: Low-intensity warfarin therapy (INR, 1.6-2.6) should be considered in elderly Korean patients with NVAF.

Key Words: - Warfarin -Atrial Fibrillation - INR 


\section{Introduction}

Atrial fibrillation (AF) is a common and serious arrhythmia that is frequently associated with the development of stroke and systemic embolism. The efficacy of warfarin therapy for the prevention of stroke or systemic embolization has been previously established. Current guidelines recommend maintaining the optimal international normalized ratio (INR) intensity range at between 2.0 to 3.0 in patients with non-valvular AF (NVAF) who are at a moderate to high risk of stroke. ${ }^{1,2}$ However, an INR in the therapeutic range (2.0-3.0) occurs in only $50 \%$ to $80 \%$ of cases even in well-monitored clinical trials. ${ }^{3}$ Moreover, optimal intensity of the INR was often lower in the observational or registry data, including the Korean AF registry, where the INR was in the therapeutic range of $42.4 \%$ of the time. ${ }^{4}$ Among the numerous causes for lower INR intensity, bleeding complications, including intracranial hemorrhage, are the main obstacles in warfarin therapy. Japanese guidelines recommend INR control between 1.6 and 2.6 in patients who are $\geq 70$ years old because old age is associated with the occurrence of severe bleeding events. ${ }^{5}$ In addition, hemorrhagic stroke occurs more frequently in Asian patients than in Caucasians. ${ }^{5}$ However, the efficacy and safety of low-intensity warfarin therapy in elderly Korean patients with NVAF is unknown. Therefore, we investigated the optimal INR target range and the risks of stroke, systemic embolism, and major bleeding based on age in Korean patients with NVAF.

\section{Subjects and Methods}

We enrolled 528 patients with NVAF who have been taking warfarin at our institution between January 2010 and July 2013. Major events were defined as ischemic stroke, systemic embolism, and major bleeding events. Major bleeding was defined based on the International Society for Thrombosis and Hemostasis criteria as clinically overt bleeding accompanied by a decrease in the hemoglobin level of at least $2 \mathrm{~g} / \mathrm{dL}$ or transfusion of at least 2 units of packed red cells, occurring at a critical site or resulting in death. ${ }^{6}$ Patients underwent warfarin therapy for $\geq 2$ years, except for those who developed major events during the follow-up period. The enrolled patients were evaluated monthly by physicians for the occurrence of ischemic stroke, systemic embolism, and major bleeding events, as well as for INR monitoring. The target INR intensity was decided by the physician-in-charge. Knowing the length of the target INR range during the oral anticoagulation period was difficult. We calculated time in therapeutic range (TTR) by the Rosendaal method. Rosendaal et al. ${ }^{7}$ proposed a method to determine the time interval between two INR measurements based on the assumption that the actual difference in INR between any two consecutive measurements was linear, and the data were interpolated accordingly. The patients were divided into two groups based on their age. We compared TTR between target INR of 2.0-3.0 and 1.6-2.6 in patients $\geq 70$ years old. Values of INR on the events were counted as INR associated with the events. The INRs that corresponded with the development of ischemic or bleeding events were assessed.

Data were expressed as the mean $\pm S D$ for continuous variables and percentages for categorical variables. Left ventricular ejection fraction (LVEF), E/E' and left atrium diameter were assessed by using two-dimensional echocardiography. All comparisons between baseline variables were assessed using the Student t-test for continuous variables and the Pearson chi-square test for categorical variables. For all analyses, a two-sided p value of $<0.05$ was considered statistically significant. Statistical analysis was performed using the SPSS software (version 18.0 for Windows, SPSS Inc., Chicago, IL, USA)

\section{Results}

The baseline characteristics of the study subjects are shown in Table 1 . The mean age of the surveyed population was $67 \pm 9$ years, and $68.4 \%$ were male. The mean follow-up period was $1035 \pm 255$ days. During the study period, 57 patients developed ischemic stroke, systemic embolism, or major bleeding events. Ischemic stroke and systemic embolism occurred in 20 patients with INR between 1.00 and 2.44 (16 ischemic strokes and 4 systemic embolisms). Major bleeding was noted in 37 patients with an INR between 1.74 and no coagulation (exceed laboratory detection capability, more than 10 [7 intracranial hemorrhages, 21 gastrointestinal bleedings, and 9 others]). The TTR during the follow-up period was $45.2 \pm 19.2 \%$. No difference was found in the TTR value between patients with and without the events. 
Table 1. Baseline clinical characteristics of the patients with and without any events

\begin{tabular}{|c|c|c|c|c|}
\hline & \multirow{2}{*}{$\begin{array}{c}\text { All patients } \\
\quad(\mathrm{n}=528)\end{array}$} & \multicolumn{2}{|c|}{ Ischemic or hemorrhagic events } & \multirow[t]{2}{*}{$P$ value } \\
\hline & & No $(n=471)$ & Yes $(n=57)$ & \\
\hline \multicolumn{5}{|l|}{ Demographics } \\
\hline Age (year) & $66.5 \pm 9.5$ & $66.2 \pm 9.6$ & $69.0 \pm 8.1$ & 0.022 \\
\hline Male (\%) & $361(68.4)$ & $322(68.4)$ & $39(68.4)$ & 0.993 \\
\hline Body mass index (kg/m²) & $24.0 \pm 3.3$ & $24.1 \pm 3.3$ & $23.2 \pm 2.8$ & 0.082 \\
\hline \multicolumn{5}{|l|}{ History } \\
\hline $\operatorname{CHF}(\%)$ & $196(37.1)$ & $172(36.5)$ & $24(42.1)$ & 0.410 \\
\hline Hypertension (\%) & $277(52.5)$ & $242(51.4)$ & $35(61.4)$ & 0.152 \\
\hline Diabetes mellitus (\%) & $129(24.4)$ & $112(23.8)$ & $17(29.8)$ & 0.316 \\
\hline CVA (\%) & $318(60.2)$ & $281(59.8)$ & $37(64.9)$ & 0.444 \\
\hline Previous MI (\%) & $32(6.1)$ & $29(6.2)$ & $3(5.3)$ & 1.000 \\
\hline $\operatorname{PAD}(\%)$ & $16(3.0)$ & $13(2.8)$ & $3(5.3)$ & 0.400 \\
\hline $\mathrm{CHADS}_{2}$ score & $2.6 \pm 1.3$ & $2.5 \pm 1.3$ & $2.8 \pm 1.2$ & 0.062 \\
\hline $\mathrm{CHA}_{2} \mathrm{DS}_{2}$ VASc score & $4.6 \pm 1.6$ & $4.5 \pm 1.6$ & $5.0 \pm 1.5$ & 0.036 \\
\hline HAS-BLED score & $2.3 \pm 1.1$ & $2.3 \pm 1.1$ & $2.6 \pm 1.2$ & 0.041 \\
\hline \multicolumn{5}{|l|}{ Mean daily dose of warfarin } \\
\hline$<3 \mathrm{mg}$ & $151(28.6)$ & $133(28.2)$ & $18(31.6)$ & 0.598 \\
\hline$\geq 3 \mathrm{mg}$ and $<5 \mathrm{mg}$ & $277(52.5)$ & $246(52.2)$ & $31(54.4)$ & 0.758 \\
\hline$\geq 5 \mathrm{mg}$ & $100(18.9)$ & $92(19.5)$ & $8(14.0)$ & 0.317 \\
\hline Time in therapeutic range (\%) & $45.2 \pm 19.2$ & $45.4 \pm 19.1$ & $43.3 \pm 19.8$ & 0.424 \\
\hline Co-administration of anti-platelet drug & $133(25.2)$ & $121(25.7)$ & $12(21.1)$ & 0.446 \\
\hline \multicolumn{5}{|l|}{ Echocardiographic findings } \\
\hline $\operatorname{LVEF}(\%)$ & $50.8 \pm 12.5$ & $51.1 \pm 12.3$ & $48.7 \pm 14.1$ & 0.230 \\
\hline $\mathrm{E} / \mathrm{E}^{\prime}(\%)$ & $13.8 \pm 6.1$ & $13.7 \pm 6.2$ & $14.9 \pm 5.5$ & 0.271 \\
\hline LA diameter (mm) & $47.9 \pm 7.6$ & $47.7 \pm 7.6$ & $49.1 \pm 7.5$ & 0.200 \\
\hline
\end{tabular}

CHF, congestive heart failure; CVA, cerebrovascular accident; LA, left atrium; LVEF, left ventricular ejection fraction; MI, myocardial infarction; PAD, peripheral artery disease

Incidence rates of ischemic or hemorrhagic events at an INR of $<2,2-3$, and $>3$ were $3.0 \%, 1.4 \%$, and $20.1 \%$ per year, respectively. In patients with ischemic or hemorrhagic events, the age, and $\mathrm{CHA}_{2} \mathrm{DS}_{2}$ VASc and HAS-BLED scores, were significantly higher compared with those in patients without events.

As mentioned earlier, patients were divided into two groups based on age. Overall, 233 patients (44\%) were $\geq 70$ years old. 
Table 2. Clinical characteristics of the patients according to age

\begin{tabular}{|c|c|c|c|}
\hline & $\begin{array}{c}\text { Age } \geq 70 \text { years } \\
\quad(n=233)\end{array}$ & $\begin{array}{c}\text { Age }<70 \text { years } \\
\quad(n=295)\end{array}$ & $P$ value \\
\hline Age (year) & $74.8 \pm 3.7$ & $60.1 \pm 7.5$ & $<0.001$ \\
\hline Male (\%) & $140(60.1)$ & $221(74.9)$ & $<0.001$ \\
\hline Body mass index (kg/m²) & $23.2 \pm 3.0$ & $24.6 \pm 3.3$ & $<0.001$ \\
\hline CHF (\%) & $78(33.5)$ & $118(40.0)$ & 0.123 \\
\hline Hypertension (\%) & $133(57.1)$ & $144(48.8)$ & 0.059 \\
\hline Diabetes mellitus (\%) & $67(28.8)$ & $62(21.0)$ & 0.040 \\
\hline CVA (\%) & $165(70.8)$ & $153(51.9)$ & $<0.001$ \\
\hline Previous MI (\%) & $14(6.0)$ & $18(6.1)$ & 0.964 \\
\hline $\operatorname{PAD}(\%)$ & $12(5.2)$ & $4(1.4)$ & 0.012 \\
\hline $\mathrm{CHADS}_{2}$ score & $3.1 \pm 1.2$ & $2.1 \pm 1.1$ & $<0.001$ \\
\hline $\mathrm{CHA}_{2} \mathrm{DS}_{2}$ VASc score & $3.8 \pm 1.3$ & $5.6 \pm 1.4$ & $<0.001$ \\
\hline HAS-BLED score & $2.8 \pm 0.8$ & $1.9 \pm 1.0$ & $<0.001$ \\
\hline \multicolumn{4}{|l|}{ Mean daily dose of warfarin } \\
\hline$<3 \mathrm{mg}$ & $76(32.6)$ & $75(25.4)$ & 0.069 \\
\hline$\geq 3 \mathrm{mg}$ and $<5 \mathrm{mg}$ & $120(51.5)$ & $157(53.2)$ & 0.695 \\
\hline$\geq 5 \mathrm{mg}$ & $37(15.9)$ & $63(21.4)$ & 0.111 \\
\hline Time in therapeutic range (\%) & $43.8 \pm 19.0$ & $46.4 \pm 19.3$ & 0.141 \\
\hline Co-administration of anti-platelet drug & $59(25.3)$ & $74(25.1)$ & 0.950 \\
\hline \multicolumn{4}{|l|}{ Echocardiographic findings } \\
\hline $\operatorname{LVEF}(\%)$ & $52.6 \pm 11.0$ & $49.5 \pm 13.5$ & 0.005 \\
\hline $\mathrm{E} / \mathrm{E}^{\prime}(\%)$ & $15.0 \pm 6.4$ & $12.9 \pm 5.8$ & 0.001 \\
\hline LA diameter (mm) & $47.4 \pm 7.9$ & $48.3 \pm 7.2$ & 0.190 \\
\hline Any events (\%) & $29(12.4)$ & $28(9.5)$ & 0.277 \\
\hline Stroke or systemic embolism (\%) & $13(5.6)$ & $7(2.4)$ & 0.055 \\
\hline Major bleeding (\%) & $16(6.9)$ & $21(7.1)$ & 0.910 \\
\hline $\mathrm{ICH}(\%)$ & $2(0.9)$ & $5(1.7)$ & 0.473 \\
\hline
\end{tabular}

CHF, congestive heart failure; CVA, cerebrovascular accident; ICH, intracerebral hemorrhage; LA, left atrium; LVEF, left ventricular ejection fraction; MI, myocardial infarction; PAD, peripheral artery disease 
More percentage of females were found in this age range, and the body mass index was significantly lower. A history of diabetes mellitus, cerebrovascular accident, and peripheral artery disease in patients who were $\geq 70$ years old was more commonly reported than that in those who were $<70$ years old. Echocardiographic findings showed that patients who were $\geq 70$ years old had slightly higher ejection fractions and higher $\mathrm{E} / \mathrm{E}$ ' values compared with those in patients who were $<70$ years old. No difference was found in the left atrium size between the two groups. In patients who were $\geq 70$ years old, $\mathrm{CHADS}_{2}, \mathrm{CHA}_{2} \mathrm{DS}_{2} \mathrm{VASc}$, and HASBLED scores were significantly higher compared with those in patients who were $<70$ years old. The TTR in patients $\geq 70$ years old was $43.8 \pm 19.0 \%$ (Table 2). However, no difference was found in the TTR value between patients with and without the events in patients who were $\geq 70$ years old $(41.5 \pm 19.6 \%$ versus $44.1 \pm 18.9 \%, p=0.492)$. When we applied the INR between 1.6 and 2.6, as recommended by the Japanese AF guidelines for patients who were $\geq 70$ years old, TTR increased from $43.8 \%$ to $58.6 \%$ (Figure 1). Stroke and systemic embolism event rates within this range slightly increased from $0.6 \%$ to $0.9 \%$ (Figure 2 ), whereas hemorrhagic event rates decreased from $1.3 \%$ to $0.2 \%$ (Figure 3). Overall, any event rates within this TTR range decreased from $1.9 \%$ to $1.2 \%$ (Figure 4 ).

\section{Discussion}

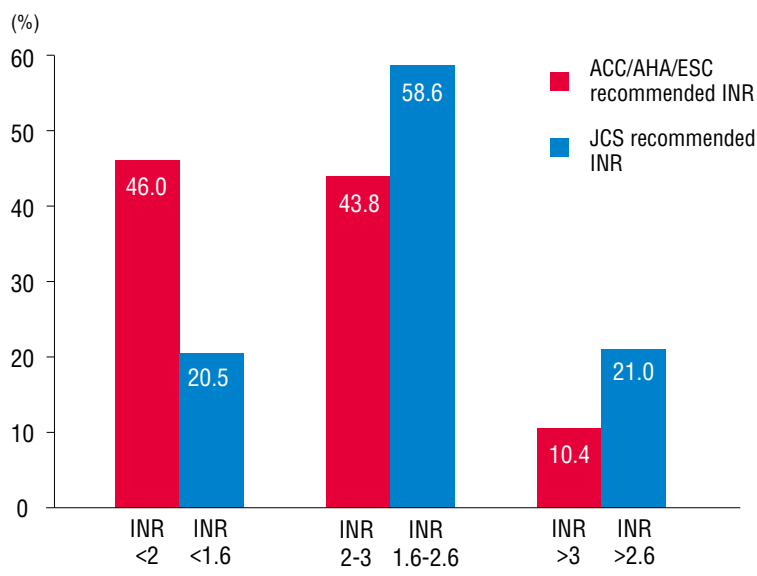

Figure 1. Changes of time in the therapeutic range among patients $\geq 70$ years old.

INR, international normalized ratio
The main finding of this study is that lower intensity warfarin therapy (INR, 1.6-2.6) is favorable in elderly Korean patients with NVAF. In Korea, the prevalence of AF increased as the population ages. AF will become a serious clinical problem in the future because elderly patients survive longer. ${ }^{8}$ The increasing incidence and prevalence of $\mathrm{AF}$ increases the likelihood of anticoagulation use in the AF population, which usually includes the elderly. Warfarin is effective for the primary and secondary prevention of both arterial and venous thromboembolic disorders. ${ }^{10,11}$ However, anticoagulation intensity correlates with bleeding risk in warfarin-anticoagulated patients. ${ }^{12-14}$ In addition, the benefits of warfarin are lost because of the higher rates of intracranial hemorrhage. In addition, racial differences may affect the risk of bleeding. ${ }^{15}$ The maintenance doses of warfarin for the Japanese and Chinese are approximately $30 \%$ and $40 \%$ lower than those for Caucasians, respectively. ${ }^{16}$ Genetic determinants of warfarin dosing may alter the effect of warfarin. ${ }^{17,18}$ In fact, the incidence of intracerebral hemorrhage was reported to be higher in Japan than in Western countries. ${ }^{19}$ Older age particularly increases the risk of bleeding in patients who have been treated with warfarin..$^{20}$ In addition, warfarin cessation after major bleeding events increases the risk of stroke, confirming that bleeding prevention can help reduce the risk of stroke in patients taking anticoagulants. Therefore, the Japanese Circulation Society has recommended a lower INR (1.6-2.6) for elderly patients due to the risk of stroke and hemorrhage. ${ }^{5}$ However, no Korean data

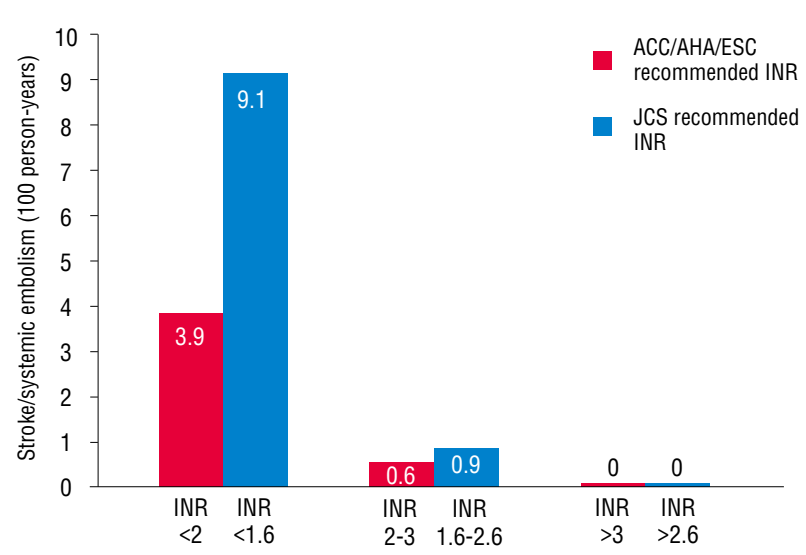

Figure 2. Stroke and systemic embolism event rates within the time in the therapeutic range in patients $\geq 70$ years old

INR, international normalized ratio 


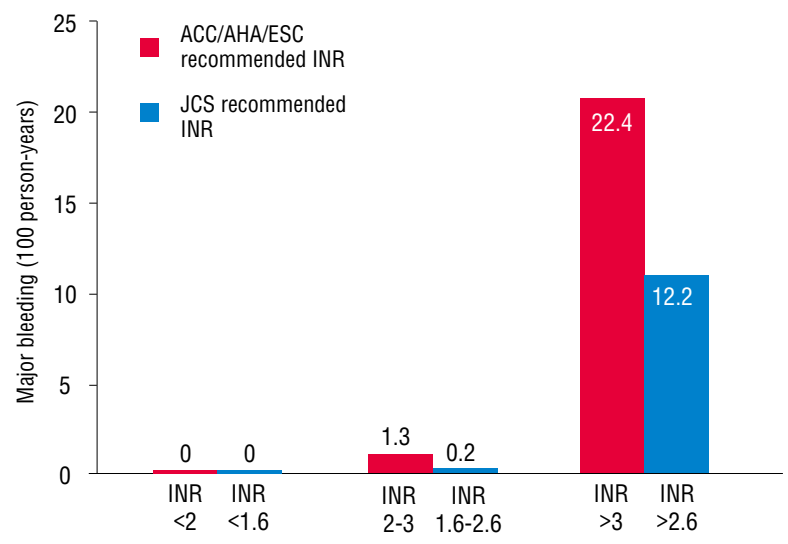

Figure 3. Hemorrhagic event rates within the time in therapeutic range in patients $\geq 70$ years old.

INR, international normalized ratio

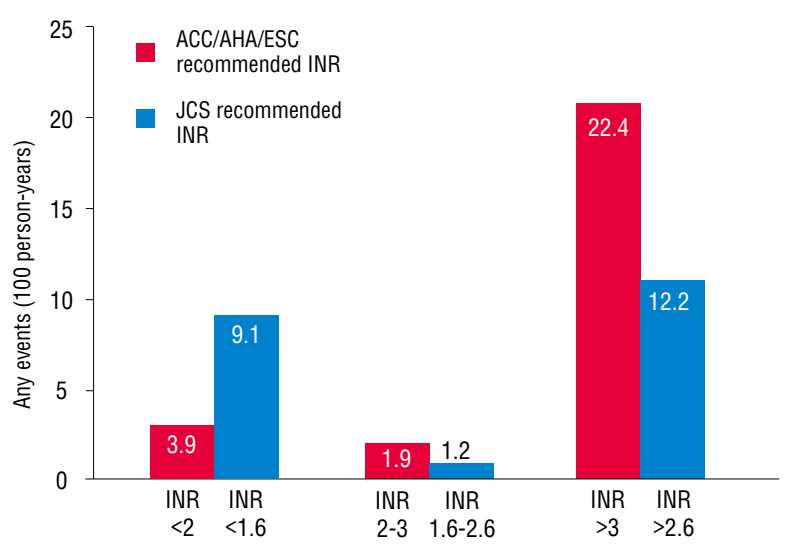

Figure 4. Any event rates within the time in therapeutic range in patients $\geq 70$ years old.

INR, international normalized ratio

\section{Conflict of interest}

All authors reported no conflicts of interest.

\section{Acknowledgements}

None

\section{References}

1) Singer DE, Albers GW, Dalen JE, Fang MC, Go AS, Halperin JL, Lip GY, Manning WJ. Antithrombotic therapy in atrial fibrillation: American College of Chest physicians evidence-based clinical practice guidelines (8th Edition). Chest. 2008;133:546S-592S.

2) Fuster V, Rydén LE, Cannom DS, Crijns HJ, Curtis AB, Ellenbogen KA, Halperin JL, Kay GN, Le Huezey JY, Lowe JE, Olsson SB, Prystowsky EN, Tamargo JL, Wann LS. ACCF/AHA/ HRS focused updates incorporated into the ACC/AHA/ESC 2006 Guidelines for the management of patients with atrial fibrillation: a report of the American College of Cardiology Foundation/American Heart Association task force on practice guidelines developed in partnership with the European Society of Cardiology and in collaboration with the European Heart Rhythm Association and the Heart Rhythm Society. J Am Coll Cardiol. 2011;57:e101-e198. 
3) Wallentin L, Yusuf S, Ezekowitz MD, Alings M, Flather M, Franzosi MG, Pais P, Dans A, Eikelboom J, Oldgren J, Pogue J, Reilly PA, Yang S, Connolly SJ; on behalf of the RE-LY investigators. Efficacy and safety of dabigatran compared with warfarin at different levels of international normalised ratio control for stroke prevention in atrial fibrillation: an analysis of the RE-LY trial. Lancet. 2010;376:975-983.

4) Shin HW, Kim YN, Bae HJ, Lee HM, Cho HO, Cho YK, Park HS, Yoon HJ, Kim H, Nam CW, Hur SH, Kim KB, Lee YS; KORAF Investigator. Trends in oral anticoagulation therapy among Korean patients with atrial fibrillation: the KORean atrial fibrillation investigation. Korean Circ J. 2012;42:113-117.

5) JCS Joint Working Group. Guidelines for pharmacotherapy of atrial fibrillation (JCS 2008). Circ J. 2010;74:2479-2500.

6) Schulman S, Kearon C; Subcommittee on control of anticoagulation of the scientific and standardization committee of the international society on thrombosis and haemostasis. Definition of major bleeding in clinical investigations of antihemostatic medicinal products in non-surgical patients. $J$ Thromb Haemost. 2005;3:692-694.

7) Rosendaal FR, Cannegieter SC, van der Meer FJ, Briét E. A method to determine the optimal intensity of oral anticoagulant therapy. Thromb Haemost. 1993;69:236-239.

8) Jeong JH. Prevalence of and risk factors for atrial fibrillation in Korean adults older than 40 Years. J Korean Med Sci. 2005;20:2630.

9) Nieuwlaat R, Capucci A, Camm AJ, Olsson SB, Andresen D, Davies DW, Cobbe S, Breithardt G, Le Heuzey JY, Prins MH, Lévy S, Crijns HJ; European Heart Survey Investigators. Atrial fibrillation management: a prospective survey in ESC member countries: the Euro heart survey on atrial fibrillation. Eur Heart J. 2005;26:2422-2434.

10) Wolf PA, Abbott RD, Kannel WB. Atrial fibrillation: a major contributor to stroke in the elderly: the Framingham Study. Arch Intern Med. 1987;147:1561-1564.

11) Stroke Prevention in Atrial Fibrillation Investigators. Adjusted-dose warfarin versus low-intensity, fixed-dose warfarin plus aspirin for high-risk patients with atrial fibrillation: stroke prevention in atrial fibrillation III randomised clinical trial. Lancet. 1996;348:633-638.

12) Choudari CP, Palmer KR. Acute gastrointestinal haemorrhage in patients treated with anticoagulant drugs. Gut. 1995;36:483-484.

13) Landefeld CS, Beyth RJ. Anticoagulant-related bleeding: clinical epidemiology, prediction, and prevention. Am J Med. 1993;95:315-328.

14) Van der Meer FJ, Rosendaal FR, Vandenbroucke JP, Briet E. Bleeding complications in oral anticoagulant therapy: an analysis of risk factors. Arch Intern Med. 1993;153:1557-1562.

15) Shen AY, Yao JF, Brar SS, Jorgensen MB, Chen W. Racial/ethnic differences in the risk of intracranial hemorrhage among patients with atrial fibrillation. J Am Coll Cardiol. 2007;50:309-315.

16) Xie HG, Kim RB, Wood AJ, Stein CM. Molecular basis of ethnic differences in drug disposition and response. Annu Rev Pharmacol Toxicol. 2001;41:815-850.

17) Lee MT, Chen CH, Chou CH, Lu LS, Chuang HP, Chen YT, Saleem AN, Wen MS, Chen JJ, Wu JY, Chen YT. Genetic determinants of warfarin dosing in the Han-Chinese population. Pharmacogenomics. 2009;10:1905-1913.

18) Daly AK. Optimal dosing of warfarin and other coumarin anticoagulants: the role of genetic polymorphisms. Arch Toxicol. 2013;87:407-420.

19) Ueda K, Hasuo Y, Kiyohara Y, Wada J, Kawano H, Kato I, Fujii I, Yanai T, Omae T, Fujishima M. Intracerebral hemorrhage in a Japanese community, Hisayama: incidence, changing pattern during long-term follow-up, and related factors. Stroke. 1988; 19:48-52.

20) Fihn SD, Callahan CM, Martin DC, McDonell MB, Henikoff JG, White RH. The risk for and severity of bleeding complications in elderly patients treated with warfarin. Ann Intern Med. 1996;124:970-979.

21) Waldo AL, Becker RC, Tapson VF, Colgan KJ; NABOR Steering Committee. Hospitalized patients with atrial fibrillation and a high risk of stroke are not being provided with adequate anticoagulation. J Am Coll Cardiol. 2005;46:1729-1736. 